\title{
Speech and Text:
}

\section{A Conclusion}

Speech and special speech: these were the key terms in my attempts to rethink the written criticism and reception of Homeric poetry. Using terms and concepts that present Homeric syntax as a flow through time rather than as a structure on the two-dimensional space of the written page, and speaking of recurrent behavior rather than of repetition, I have tried to devise a vocabulary that views speech, and Homeric formulaic speech in particular, as a medium in its own right, rather than as a style that is defined with respect to the written styles of later periods.

The conception of orality that was in the forefront in the preceding pages is different from the historical or literary conceptions that view orality as the stage preceding literacy, or as a kind of literature that is different from our own. Adopting the ahistorical stance of the discourse analyst, I have tried to approach Homeric poetry from the point of view of speech, and speaking, the most natural way of using language. Still, the investigation has been a historical one in the philological sense of that term: we have been reconstructing something from the past, not a text or some other physical reality, but a medium. This medium of speech has become obliterated by the opposite medium of writing which has carried Homeric poetry through the ages.

The reconstruction of speech is in a sense the deconstruction of text. The presentation of Homeric passages in the form of the speech units that formed the basis of almost all the operations in the preceding chapters may seem cumbersome to some readers. Yet such a reaction merely confirms that categories of textual reception were disabled in the attempt to detextualize the salient features of Homeric style, and redescribe them in terms 
of the speech of which the text is a transcription. No speech that is transcribed in such a way as to highlight the typical features of the spoken medium makes for easy reading.

Yet something is missing here, something that formed the core of the conception of speech that I presented in the preceding chapters, even that of writing in Chapter 2. To speak of the Homeric text as the transcription of speech is an oversimplification insofar as neither speech nor text are onetime events. I have spoken at some length of recurrence at various junctures in the preceding argument, ${ }^{1}$ and we may now return to this concept in our final assessment of the findings of this study.

I argued that recurrence, not as the repetition of identical phrases, but as routinized behavior, is an essential feature of speech, the basic medium of language. In ordinary discourse the regularization and normalization resulting from recurrence is a matter of grammar, or rather, of the process of becoming grammatical. ${ }^{2}$ In the special discourse of the Homeric performance, analogously, the result of recurrence is regularization of the prosody of speech in the form of meter. Meter is synchronically a matter of stylization, one of the aspects of poetry in speech; diachronically, however, meter is a matter of becoming metrical, of speech into poetry.

Unlike the grammarian of a living and continuously evolving language, the grammarian of Homeric special speech is in a position to study the final result of regularization, the point after which no change will ever occur. This is, of course, the Homeric text as it is transmitted in the medieval codices. In fact, this text is itself the result of recurrence, of numerous redactions in the course of which the process of normalization and regularization, inherent already in the process by which speech becomes special speech, reached its final stage.

The writing of Homer, as I argued in Chapter 2, was originally a matter of transcription, of the transcoding of one medium (speech) into another (text), in order to facilitate future performances. ${ }^{3}$ But there is no reason to suppose that the first transcripts were anything like the text we possess today. In this regard it may be helpful to listen to students of traditions of

1 See Chapters I, 7, and 8 .

2 In linguistics the term "grammaticalization" is used. See Heine et al. I99I; Hopper and Traugott 1993. See also Chapter 8.

${ }^{3}$ See Nagy's definition (I992a: 42) of transcript: "A transcript is not the equivalent of performance, though it may be an aid to performance." Cf. Nagy I996: I I2. I would add that in a transcript the act of narration is not yet fictionalized: the text is not meant to stand on its own as inscribed discourse. 
special speech who are in a position to produce the transcription of speech that they have witnessed themselves: "The measuring out of long runs of lines with equal numbers or syllables, moras, or feet does not occur in audible texts from cultures whose verbal arts are not under the direct influence of literary traditions. In most languages, such fine-grained metrical schemes require an atomization of speech sounds that is precisely the forte of alphabetic and syllabic writing systems." ${ }^{4}$

Such imposition of the categories of the writing system cannot be due to transcription as a one-time event, the creation of an unedited transcript of a performance, to be copied as is into the future. Writing too was a process, not of mere transcription, but of textualization, ${ }^{5}$ the gradual transformation of words from elements of sound into elements of orthography. Such a transformation is crucially bound up with the textual perception of meter as something regular. Writing, I submit, is responsible in the last resort for meter as we know it, not as the emergence of regular rhythmical patterns from the prosody of speech, but as the principle determining the poetic style of the text.

A case in point is the frequent Homeric phenomenon of diectasis 'drawing out' a contracted vowel over three moras, as in métióōnto or mēkhanáasthai, where the long vowel $\bar{o}$ or $\bar{a}$ has been distended so as to occupy a metrical space that is longer than one longum. Such forms are often seen as artificial creations of the epic Kunstsprache, inadmissible in the ordinary language and created to avoid the "impossible" single-short rhythm of the "natural" forms mèkhanâsthai and mêtiônto (- -- and $-\cup-\cup) .{ }^{6}$ I would rather hold that the artificiality is a matter of spelling, and that the diectasis is a strategy to make the meter regular in the text, whereas what happens in the reality of the performance is merely the marked pronunciation of a certain word. In other words, a phonetic entity has been converted into an orthographic item, part of a textualization of the epic tradition that cannot

4 Tedlock 1983: 8. Cf. Hymes I994. See also Chapter 6.

${ }^{5}$ For the difference between transcription and textualization, $c f$. the German terminological distinction between Verschriftung 'textification' and Verschriftlichung 'textualization' proposed by Oesterreicher (1993), who usefully points out (27I) that pure transcription, without any interference of the transcribing, recording medium, is in principle possible only with the help of modern recording technology. Thus in practice any transcription of speech into writing brings in elements belonging to the latter medium, however superficial or unimportant.

${ }^{6}$ E.g., Chantraine I 948-53: 75-83. Janko rightly stresses (I992: I 7) that diectasis forms are signs of innovation in the Kunstsprache, in that the bards prefer them over the older, uncontracted forms $\mu \eta \chi \alpha v \underline{\alpha} \varepsilon \sigma \theta \alpha \imath$ and $\mu \eta \tau \imath \underline{\alpha} \sigma o v \tau$; yet he also treats the distended words as forms rather than as spellings. 
but have contributed to a further, and final, regularization of the dactylic hexameter. ${ }^{7}$

What I propose, then, is that the increasing textualization of the Homeric tradition is an extension of the process of regularizing the prosody of ordinary speech into meter. In other words, the special speech of the Homeric tradition, with its increasingly rigid meter and its need to sustain itself across performances, has an in-built tendency to textualization, to inscribe itself, as a result of an increasingly textual reception. This would seem a paradox at first sight: we have been concerned, as I just suggested, with the reconstruction of the medium of speech, and so with the deconstruction of the text. But if we have now reconstructed a medium that tends to textualize itself, has not our own investigation deconstructed itself, undermining the methodology that it asserts?

The paradox disappears when we realize that the textualization of the Homeric tradition has been only a very partial one. Special speech becomes written, and so poetry, but the aspects of it that undergo textualization are precisely those aspects by which it is marked with respect to ordinary speech: the prosodic regularity of meter. In other respects Homeric discourse has remained remarkably close to speech in its typical segmentation and syntactic progression. These features have caused enough baffled reactions, in ancient and modern times, to justify the attempts made in the preceding chapters to rethink some of our textual terminological apparatus. And if our notion of special speech has inherent affinities with the text that Homer has become, so it has with the speech from which that text originates.

\footnotetext{
7 See Gentili I988: 23 I.
} 